\title{
Colonic Slow Transit Can Cause Changes in the Gut Environment Observed in the Elderly
}

\author{
Seong-Eun Kim \\ Department of Internal Medicine, Ewha Womans University School of Medicine, Seoul, Korea
}

\section{Article: Colonic transit time is a driven force of the gut microbiota composition and metabolism: in vitro evidence Tottey W, Feria-Gervasio D, Gaci N, et al \\ (J Neurogastroenterol Motil 2017;23:124-134)}

Aging process has been recognized to be associated with an increased risk of constipation. Some studies reported a longer mean colonic transit time in the healthy elderly. ${ }^{1}$ Age-related changes in both the neurons and the receptors of the enteric nervous system had been also reported in other studies. ${ }^{2,3}$ However, the evidence to support age itself as an independent risk factor for constipation have been conflicting. The opposite opinions are as follows: (1) the slow transit in the elderly is commonly the result of increased and prolonged intake of the relating drugs, reduced intake of dietary fiber, and relatively low levels of physical exercise, (2) some studies showed no significant change of colonic transit time with advancing age, ${ }^{4,5}$ and (3) the prevalence of constipation in the elderly living in the community is indeed only $50 \%$, although it is even higher in nursing home residents, with $74 \%$, using daily laxatives. ${ }^{6}$ Therefore, it is difficult to conclude that colonic slow transit in the elderly is just a physiological consequence. ${ }^{7}$

This elegant article seems to have the premise that the slow colon transit is a natural change in the elderly. ${ }^{8}$ Also, they showed that the increased transit time could change the gut microbiota composition and the metabolism which also could be seen in aged gut, using an explorative and creative system. It was an innovative work. Until now, most studies did not show directly that the increased transit could affect the gut microbiota composition as well as their metabolites. However, more precisely, it would be rather reasonable to consider that colonic slow transit could modify the microbiota composition to the one shown in old age. Slow transit might be the most contributing factor to the gut environment in the elderly among multiple factors associated with old age, although it may not be the whole cause.

The 3-stage Environmental Control System for Intestinal Microbiota (3S-ECSIM) used in this article could show some mechanisms from the association between flora and gut environment. However, the unavoidable limitation as an in vitro system should be considered. The various factors of in vivo such as daily diet, co-morbidity, markers of inflammation, and medications were excluded. ${ }^{9}$ The variously set retention times in each reactor were not realistic. In addition, the in vitro system could not simulate the peristalsis of colon.

Nevertheless, it is a very valuable study to show that the increased colon transit would change the gut microbiota composition with the environmental characteristics observed in the aged gut. In addition, it should be questioned whether the microbiota composition could be changed to the initial composition if the transit time would be shortened in turn.

Received: December 14, 2016 Revised: None Accepted: December 14, 2016

(a) This is an Open Access article distributed under the terms of the Creative Commons Attribution Non-Commercial License (http://creativecommons. org/licenses/by-nc/4.0) which permits unrestricted non-commercial use, distribution, and reproduction in any medium, provided the original work is properly cited.

*Correspondence: Seong-Eun Kim, MD Department of Internal Medicine, Ewha Womans University School of Medicine, 1071, Anyangcheon-ro, Yangchun-gu, Seoul 07985, Korea Tel: +82-2-2650-2845, Fax: +82-2-2650-2076, E-mail: kimse@ewha.ac.kr 


\section{Financial support: None.}

\section{Conflicts of interest: None.}

\section{References}

1. Madsen JL, Graff J. Effects of ageing on gastrointestinal motor function. Age Ageing 2004;33:154-159.

2. Gomes OA, de Souza RR, Liberti EA. A preliminary investigation of the effects of aging on the nerve cell number in the myenteric ganglia of the human colon. Gerontology 1997;43:210-217.

3. Takahashi T, Qoubaitary A, Owyang C, et al. Decreased expression of nitric oxide synthase in the colonic myenteric plexus of aged rats. Brain Res 2000;883:15-21.
4. Brogna A, Ferrara R, Bucceri AM, Lanteri E, et al. Influence of aging on gastrointestinal transit time. An ultrasonographic and radiologic study. Invest Radiol 1999;34:357-359.

5. O'Mahony D, O'Leary P, Quigley EM. Aging and intestinal motility: a review of factors that affect intestinal motility in the aged. Drugs Aging 2002;19:515-527.

6. Rao SS, Go JT. Update on the management of constipation in the elderly: new treatment options. Clin Interv Aging 2010;5:163-171.

7. Gallagher P, O'Mahony D. Constipation in old age. Best Pract Res Clin Gastroenterol 2009;23:875-887.

8. Tottey W, Feria-Gervasio D, Gaci N, et al. Colonic transit time is a driven force of the gut microbiota composition and metabolism: in vitro evidence. J Neurogastroenterol Motil 2017;23:124-134.

9. Claesson MJ, Jeffery IB, Conde $\mathrm{S}$, et al. Gut microbiota composition correlates with diet and health in the elderly. Nature 2012;488:178-184. 